\title{
Histological aspects of the esophagus in guinea pigs (Cavia porcellus)
}

\author{
Vasile RUS ${ }^{1}$, Flavia RUXANDA ${ }^{1 *}$, Aurel DAMIAN ${ }^{1}$, Călin NUȚ ${ }^{1}$, Cristian MARTONOS ${ }^{1}$, Gabriela DOGARU ${ }^{2}$, \\ Viorel MICLĂUȘ ${ }^{1}$, Adrian Florin GAL ${ }^{1}$ \\ ${ }^{1}$ Faculty of Veterinary Medicine, University of Agricultural Sciences and Veterinary Medicine Cluj-Napoca, \\ Calea Mănăştur 3-5, Cluj-Napoca, 400372, Romania \\ 2"Iuliu Hațieganu" University of Medicine and Pharmacy Cluj-Napoca, Romania, Department of Medical \\ Rehabilitation, Victor Babeș Str., No. 43, 400012 Cluj-Napoca, Romania \\ *corresponding author: flavia.ruxanda@usamvcluj.ro
}

Bulletin UASVM Veterinary Medicine 76(2)/2019

Print ISSN 1843-5270; Electronic ISSN 1843-5378

doi:10.15835/buasvmcn-vm:2019.0014

\begin{abstract}
:
The aim of this study is the detailed description of the esophageal microscopic structure in guinea pigs. Fragments from the cervical, thoracic and abdominal segments of the esophagus were processed for classical paraffin embedding and the sections were stained by hematoxylin-eosin and Goldner's trichrome methods. The esophagus in guinea pigs is lined by keratinized stratified squamous epithelium and there are no glands in the lamina propria and the submucosa. The muscularis mucosae is formed by smooth muscle cells disposed longitudinally. The muscularis externa is formed by striated muscle cells disposed on 3 layers in the first 2 thirds of the esophagus, while in some regions of the abdominal segment's circumference, the cells form 4 layers.
\end{abstract}

Keywords: esophagus, guinea pig, microscopic structure

\section{Introduction}

The esophagus is a cavitary organ and the wall comprises 4 layers (from the inside to the outside): mucosa, submucosa, muscularis externa and adventitia (in pre-diaphragmatic segment) or serosa (in the post-diaphragmatic segment) (Kerr, 2002; Miclăuș et al., 2017). The mucosa is formed by epithelium, lamina propria and muscularis mucosae. Usually, the esophagus is lined by stratified squamous epithelium. Depending on the species, the epithelium can be keratinized. Thus, in ruminants (Miclăus et al., 2017), various birds (Rus et al., 2009), chinchillas (Rus et al., 2018), the epithelium is keratinized.

The lamina propria is formed by a relatively dense connective tissue and is separated from the submucosa by muscularis mucosae. The muscularis mucosae in guinea pigs is formed by smooth muscle cells disposed longitudinally (Kamikawa et al., 1985; Kerr, 2002). In some species, exocrine glands are present in the lamina propria and submucosa (Rus et al., 2018).

The muscularis externa in most of the species is formed of 2 layers (inner circular and external longitudinal). A lot of species of mammals have striated muscles cells in the muscularis externa (Whitmore, 1982; Kerr, 2002; Rus et al., 2018). Due to the fact that both types of muscle cells (smooth and striated) exist in the structure of the esophagus, this organ is used in numerous studies of physiology and pharmacodynamics. The three types of neurokinin receptors are homologous in guinea pigs and human, consequently a lot of 
pharmacological studies are made on guinea pigs, rather than rats (Kerr, 2002).

The aim of this study is the detailed description of the esophageal microscopic structure in guinea pigs.

\section{Materials and methods}

In this study, 3 male guinea pigs were used (diagnosed with lobar pneumonia and brought for complete necropsy). We harvested transversal fragments from the cervical, thoracic and abdominal segments of the esophagus. The fragments were fixed by immersion in Stieve solution (24 hours) and were later on processed for classical paraffin embedding. Sections of $5 \mu \mathrm{m}$ thickness were subsequently obtained from each segment and they were stained using 2 methods: hematoxylin-eosin and Goldner's trichrome, respectively. The slides were examined under light microscope (Olympus BX41) and pictures were captured with an Olympus E 330 photo camera. The pictures were digitally processed using an image editing software (Adobe Photoshop CS2).

\section{Results and discussion}

In guinea pigs, the diameter of the esophagus is comparable throughout its entire length. In the cervical segment of the esophagus, the wall is formed by 4 layers: mucosa, submucosa, muscularis externa, and adventitia (Figure 1). The mucosa and submucosa form longitudinal folds, thus the lumen of the organ appears starshaped on the section. The mucosa is formed by epithelium, lamina propria and muscularis mucosae. The stratified squamous epithelium is keratinized and consists of 4 layers: basal, spinous, granular and keratinized (Figure 2). The epithelium is similar to the epidermis but there are some differences. The basal layer consists of one layer of cuboidal to columnar cells and it is the only layer similar to the epidermis. The spiny layer is thinner than the one in the epidermis and is formed only by 3-4 rows of polyhedral cells. Then there are several layers of increasingly flattening cells, but without the presence of keratin precursors in their cytoplasm, as described in the granular layer of the epidermis. These cells have an intermediary aspect between the spinous and granular cells. The granular layer is thick containing 5-6 rows of cells (approximately twice as many as in the epidermis), where dark keratin precursors are distinguished, giving the typical granular aspect. The keratinized layer is thicker, formed by keratinized cells but the keratin has a different aspect in comparison to the keratin of the epidermis. The aspect of the keratin is less dense than the one of the epidermis. The superficial cells have the tendency to detach forming flaps. These differences between esophageal epithelium and the epidermis are probably due to the fact that the esophageal epithelium is permanently wetted by secretions or food passing by. The lamina propria is thicker and is formed by a relatively dense connective tissue. The muscularis mucosae is well developed and it is formed by smooth muscle cells with a longitudinal arrangement. The submucosa is very well developed and is formed by loose connective tissue. This loose connective tissue allows mobility between the mucosa and the muscularis externa and also enters in the axis of each longitudinal fold. The muscularis externa is formed by striated muscles cells disposed in layers. From outside to inside we find 3 layers: external, middle and internal. The external layer is thinner and formed by cells with longitudinal orientation. The middle layer is thicker, its cells having a circular disposition. In the internal layer, the cells have generally a longitudinal arrangement but this layer is not present on the entire circumference (it is present on less than half of esophageal circumference) (Figure 3). The adventitia is the outmost layer of the esophagus and is formed by a very well vascularized and innervated loose connective tissue.

The thoracic segment of the esophagus (Figure 4) is almost structurally identical to the one described in the cervical area.

The structure of the abdominal segment of the esophagus is similar to the other segments but we observe some differences in the muscularis externa. The cells of the muscularis externa have a less orderly orientation in comparison to other segments (Figure 5). In some areas of the esophagus' circumference, we find 3 layers (from inside to outside: longitudinal, circular, and longitudinal) and in other regions, we find 4 layers (from inside to outside: circular, longitudinal, circular, and longitudinal). In the 4 layered regions, the orientation of each layer's muscles cells is slightly plexiform. 


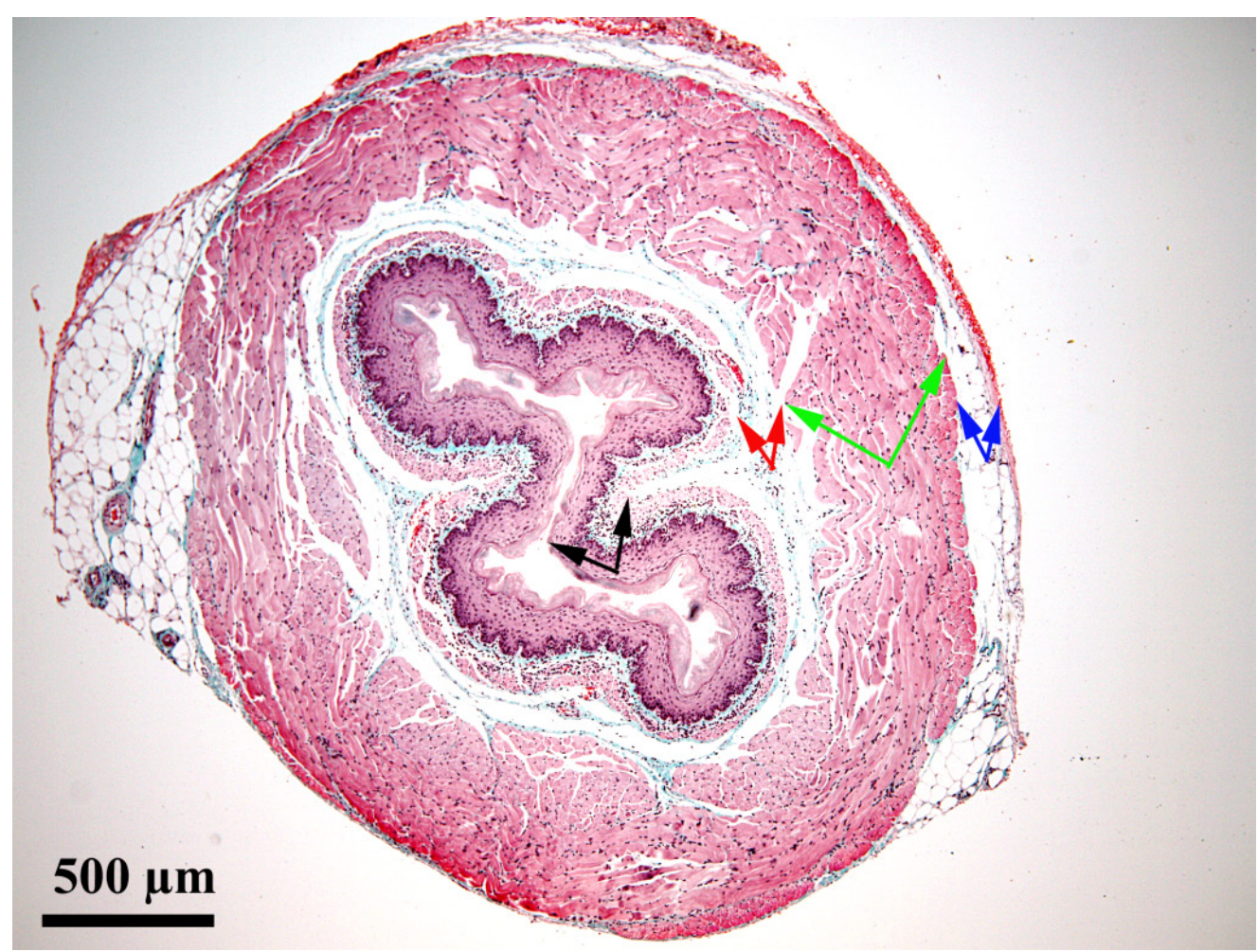

Figure 1. Cervical segment of the esophagus; Goldner's trichrome stain; black arrow - mucosa; red arrow submucosa; green arrow - muscularis externa; blue arrow - adventitia

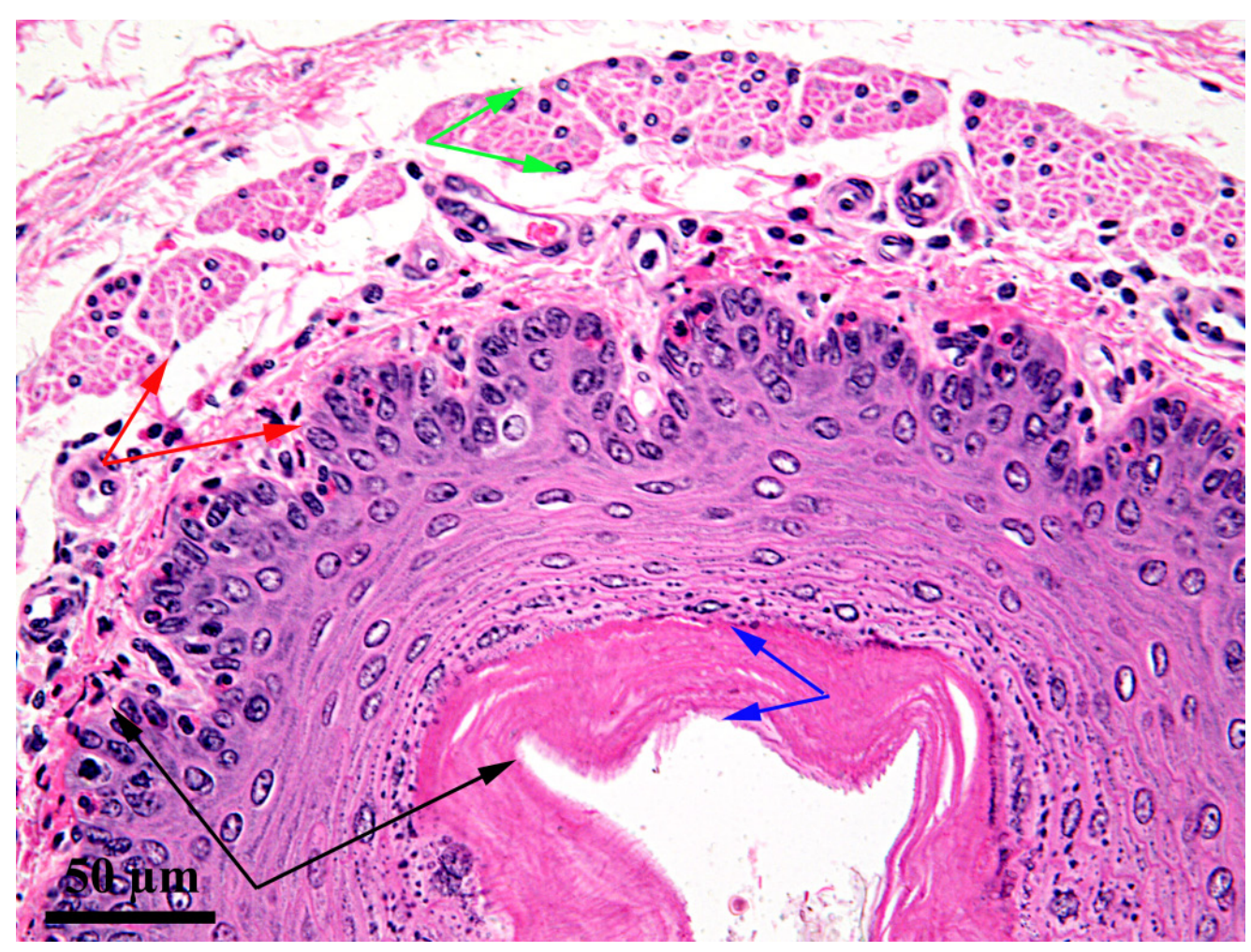

Figure 2. Mucosa of the cervical segment of the esophagus; hematoxylin-eosin stain; black arrow - epithelium; red arrow - lamina propria; green arrow - muscularis mucosa; blue arrow - keratin layer 


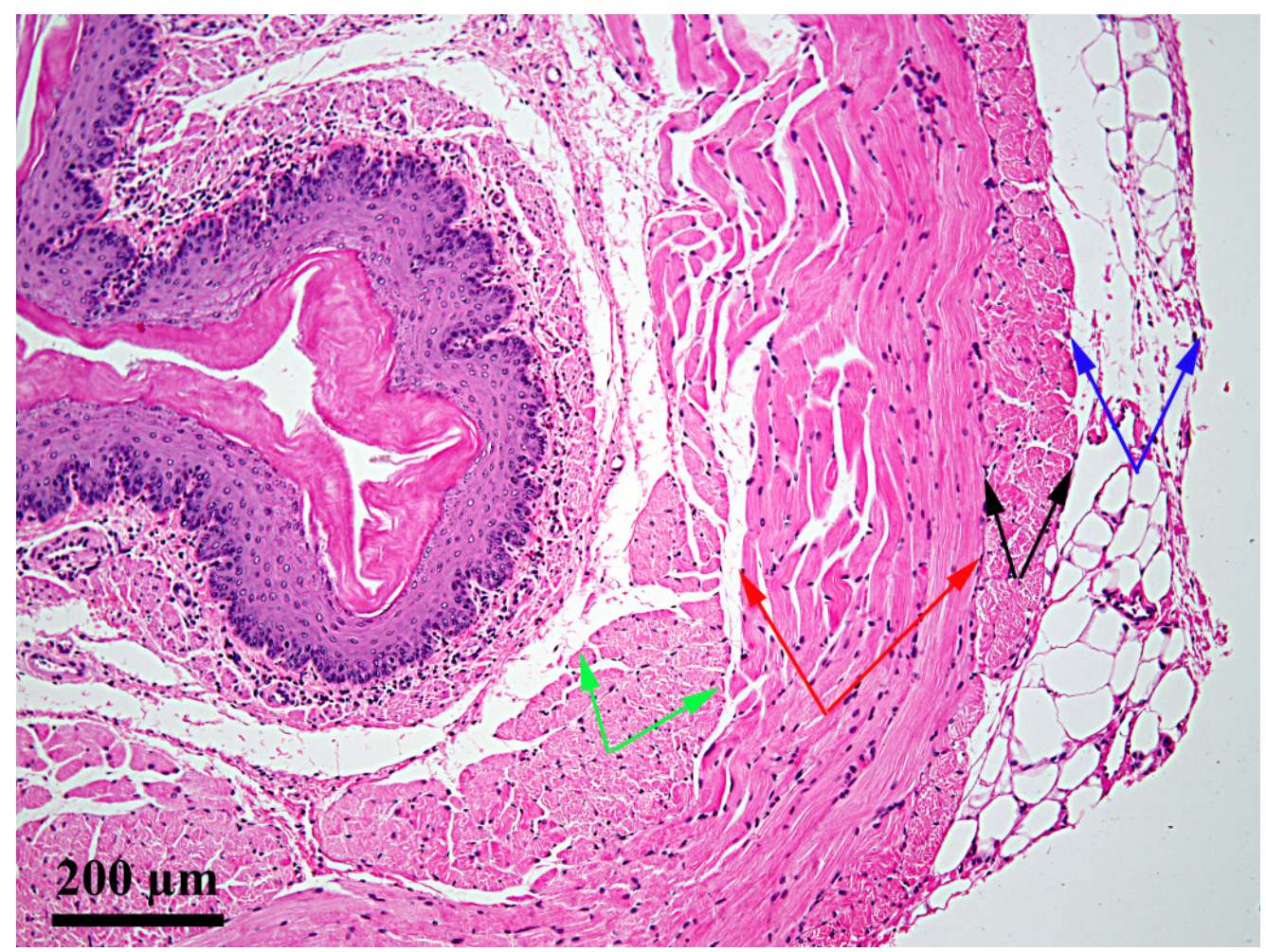

Figure 3. Muscularis externa and adventitia of the cervical segment of the esophagus; hematoxylin-eosin stain; black arrow - external layer; red arrow - middle layer; green arrow - internal layer; blue arrow - adventitia

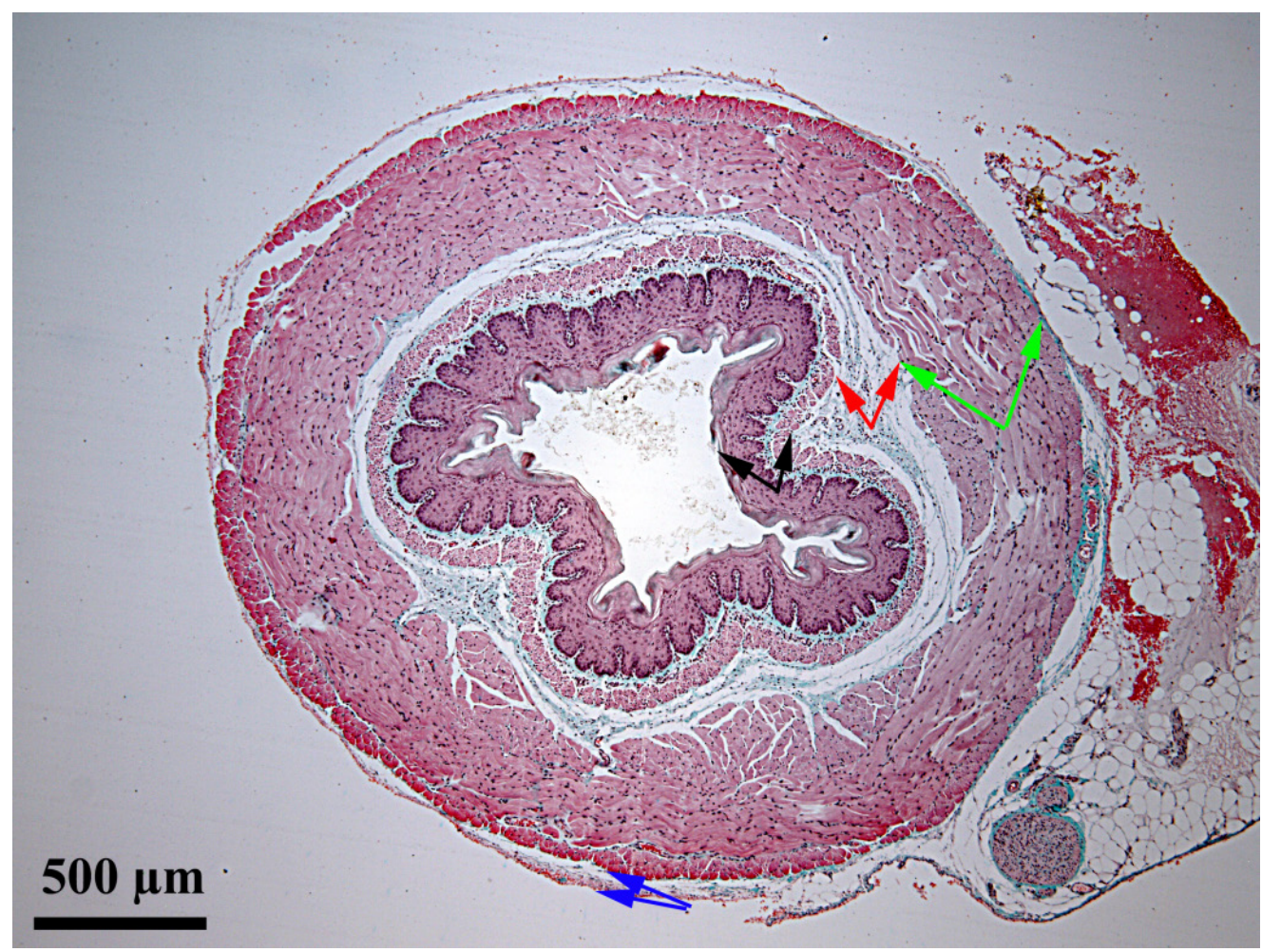

Figure 4. Thoracic segment of the esophagus; Goldner's trichrome stain; black arrow - mucosa; red arrow submucosa; green arrow - muscularis externa; blue arrow - adventitia 


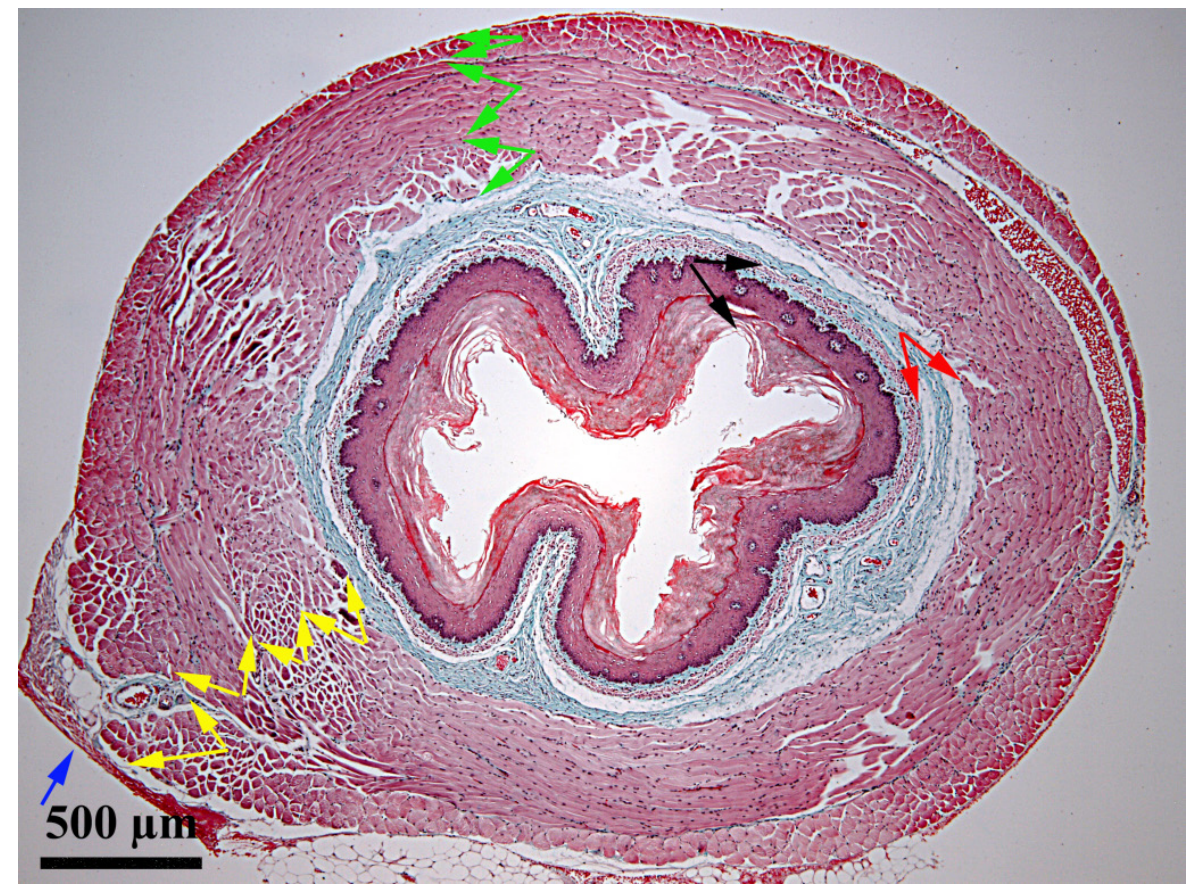

Figure 5. Abdominal segment of the esophagus; Goldner's trichrome stain; black arrow - mucosa; red arrow - submucosa; green arrow - muscularis externa - 3 layers; yellow arrow - muscularis externa - 4 layers; blue arrow - serosa

The esophagus in guinea pigs has the same structure in the cervical and thoracic segments. Regarding the abdominal segment, the structure is almost the same with some differences in the muscularis externa, where we find 4 layers in some regions of the esophagus' circumference. Regarding the muscularis mucosae, same structure and distribution was described by other authors (Kamikawa et al., 1985; Kerr, 2002). In terms of muscularis externa, our results are not identical with the results presented by other authors. Whitmore (1982) and Kerr (2002) described 2 muscle layers and some bundles of cells with other orientation between them.

The literature data highlights that in most mammal species the musculature of the esophagus is organized on two layers (Ingelfinger, 1958; Guber, 1968; Guber, 1978; Samarasinghe, 1972) with a typical circular layout in the internal part and longitudinal arrangement in the outer layer (Whitmore, 1982). On the other hand, Francis (1974) reported four layers of muscle cells in the esophagus of guinea pigs.

A more particular situation occurs in primates, marsupials, cats, and humans where the muscularis externa is formed by striated muscles cells in some segments, while other regions are composed of smooth muscle cells. The transition between the two types of muscles occurs in the middle third of the esophagus (Ingelfinger, 1958; Code and Schlegel 1968; Schofield, 1968; Floyd and Morrison, 1975; Weisbrodt, 1976; Enzmann et al., 1977; Dodds et al., 1978). There are also authors who claim that the portion with smooth muscle is significantly higher than the one with striated muscle in some species. Thus, Raica et al., (2004) state that, in humans, only about $5 \%$ of the first third contains striated muscle, followed by a short transition area, so that the two distal thirds contain only smooth muscle rigorously organized on two planes: internal circular and external longitudinal.

\section{Conclusions}

The esophagus in guinea pigs is lined by keratinized stratified squamous epithelium and there are no glands in the lamina propria and the submucosa. The muscularis mucosae is formed by smooth muscle cells disposed longitudinally. The muscularis externa is formed by striated muscle cells disposed on 3 layers in the first 2 thirds of the esophagus, while in some regions of the abdominal segment's circumference, the cells form 4 layers. 
Acknowledgments. This research did not receive any specific grant from funding agencies in the public, commercial, or not-for-profit sectors.

\section{References}

1. Code CF, Schlegel JF (1968). Motor action of the esophagus and its sphincters. Handbook of Physiology, Sect. 6, IV, 1821-1839.

2. Dodds WJ, Steff JJ, Stewart ET, Hogan WJ, Arndorfer RC, Cohen EB (1978). Responses of feline esophagus to cervical vagal stimulation. Am J Physiol, 235: E63-E74.

3. Enzmann DR, Harell GS, Zboralske FF (1977). Upper esophageal response to intraluminal distention in man. Gastroenterology, 72:1292-1298.

4. Floyd K, Morrison JFB (1975). The mechanical properties of oesophageal striated muscle in the cat and sheep. J of Physiol, 248: 717-724.

5. Francis DA (1974). Observations on the structure and innervation of the oesophagus of the guinea pig. B.Sc. Thesis, Manchester University.

6. Gruber H (1968). Über Struktur und Innervation der quergestreiften Muskulatur des Oesophagus der Ratte. Zeitschrift für Zellforschung Doi.org/10.1007/ BF00364313

7. Gruber H (1978). Motor innervation of the striated oesophagus muscle. Part I (intramural distribution of the right and left vagus nerves in rat oesophagus as revealed by the glycogen depletion technique). J of Neurol Sci, 36: 41-53.
8. Ingelfnger FJ (1958). Oesophageal motility. Physiol Rev, 38: 533-581.

9. Kamikawa Y, Uchida K, Shimo Y (1985). Heterogeneity of muscarinic receptors in the guinea pig esophageal muscularis mucosae and ileal longitudinal muscle. Gastroenterol, 88(3):706-16.

10. Kerr KP (2002). The guinea-pig oesophagus is a versatile in vitro preparation for pharmacological studies, Clin and Exp Pharmacol and Physiol, 29; 1047-1054.

11. Miclăuș V, Gal AF, Rus V, Ruxanda F, (2017). Histologie specială și embriologie, Editura AcademicPres, ClujNapoca

12. Raica M, Mederle O, Căruntu ID, Pintea A, Chindriș AM (2004). Histologie teoretică și practică, Ed. Brumar, Timișoara.

13. Rus V, Ghiurco FI, Constantinescu R, Miclăuș V (2018). Histological aspects of the esophagus at Chinchilla (Chinchilla lanigera), Annals of R.S.C.B., XXII(2): 11-17.

14. Rus V, Miclăuș V, Nadăș GC, Cadar D (2009). Structural particularities of the white stork (Ciconia ciconia) esophagus, Annals of RSCB, XIV(1): 177-179.

15. Samarasinghe DD (1972). Some observations on the innervation of the striated muscle in the mouse oesophagus - an electron microscope study. J of Anat, 112: 173-184.

16. Schofield GC (1968). Anatomy of muscular and neural tissues in the alimentary canal. Handbook of Physiology, Sect. 6, IV, 1579-1627.

17. Weisbrodt NW (1976). Neuromuscular organisation of esophageal and pharyngeal motility. Archiv of Intern Med, 136: 524-531.

18. Whitmore I., (1982). Oesophageal striated muscle arrangement and histochemical fiber types in guinea-pig, marmoset, macaque and man, J. Anat., 134(4): 685-495. 